\title{
Place of Ultrasonographic in Screening Brain Lesions in Premature Newborn at Cotonou
}

\author{
Hermione Patricia Yekpe Ahouansou1*, Léila Tossa Bagnan², Olivier Biaou1, \\ Kofi Mensa Savi de Tove ${ }^{3}$, Mireille Sotchenou${ }^{4}$, Vicencia Boco' ${ }^{1}$ \\ ${ }^{1}$ National Hospital Center Koutoukou Hubert Maga, Medical Scanning Unit, University of Abomey-Calavi, \\ Cotonou, Benin \\ ${ }^{2}$ National Hospital Center Koutoukou Hubert Maga, Clinic of Pediatrics and Genetics, University of \\ Abomey-calavi, Cotonou, Benin \\ ${ }^{3}$ Departmental Centre of Borgou, Medical Scanning Unit, University of Parakou, Parakou, Benin \\ ${ }^{4}$ Polytechnic College of Abomey-Calavi, Medical Scanning Department, Cotonou, Benin \\ Email: "Yfrida pat@yahoo.fr
}

Received 4 January 2016; accepted 7 March 2016; published 11 March 2016

Copyright (C) 2016 by authors and Scientific Research Publishing Inc.

This work is licensed under the Creative Commons Attribution International License (CC BY).

http://creativecommons.org/licenses/by/4.0/

(c) (i) Open Access

\section{Abstract}

Goal: The goal of this study is to define the epidemiological profile and identify the different brain lesions diagnosed in ultrasonography in preterm infants in Benin environment. Patients and methods: It is a prospective cross-sectional study of analytical aiming. It took place over a period of 6 months, from May $1^{\text {st }}$ to October 31 ${ }^{\text {st }}, 2012$ at the National Hospital University Centre Koutoukou Hubert Maga in neonatal units and medical scanning unit. It covered 105 premature newborn, classified into the very prematurity and the moderate prematurity. Results: The very premature represented $35.2 \%$ and the moderate premature $64.8 \%$, with an average of $33.5 \%$ and 1.9 of standard deviation. The average age when implementing ultrasonographic transfontanellar was $7.2 \pm 4.6$ days old. The lowest birth weight was observed in very premature with $p=0.0025$. The nasopharyngeal septum pellucidum was the most found lesions in 46 preterm infants $(43.8 \%)$ with no statistically significantly difference in two groups, followed by the ventricular haemorrhage found in 21 preterm infants accounting for $20 \%$, and the grade 1 or sub-ependymal haemorrhage prevailed in 14 premature accounting for $66.7 \%$, afterward periventricular leukomalacia in 4 premature infants and hydrocephalus in 2 premature. Conclusion: The nasopharyngeal septum pellucidum and the sub-ependymal ventricular haemorrhage were the predominant anomalies in premature infants followed by leukomalacia.

\section{Keywords}

Ultrasonographic Transfontanellar, Preterm Infant, Nasopharyngeal Septum Pellucidum,

\footnotetext{
${ }^{*}$ Corresponding author.
}

How to cite this paper: Ahouansou, H.P.Y., Bagnan, L.T., Biaou, O., de Tove, K.M.S., Sotchenou, M. and Boco, V. (2016) Place of Ultrasonographic in Screening Brain Lesions in Premature Newborn at Cotonou. Open Journal of Radiology, 6, 10-17. http://dx.doi.org/10.4236/ojrad.2016.61002 


\section{Introduction}

The recent systematic review by Blencowe of mortality and maternal morbidity in the world suggests that about 15 million of newborn in 2010 were premature [1]. The highest rates of premature birth worldwide accounting for $85 \%$ are in Africa and Asia, where health systems are poor and access to health services is limited [2]. Prematurity is one of the main causes of hospitalization and death of the newborn in neonatal [1] [3]. In Benin, it represented 10\% of admissions in neonatology in the years 2008 and 2009 [4]. The pathology and risks of prematurity in the first week of life are related to the overall functional immaturity of its organs [5] [6]. Hemorrhage is common in neonatal period [7]. The sequel is important especially in intracranial locations where they can reach $40 \%$ [8]. The complicated cerebrals reports are intraventricular hemorrhage, the periventricular leukomalacia, the disease of the white substance and post-hemorrhagic ventricular dilatation [5] [9].

The ultrasonography transfontanellar (USG transfontanellar) is a harmless method, non-invasive, non-irradiating, repetitive and affordable cost. It is widely used for the detection of brain lesions [9]-[13]. In developing countries, especially in West Africa, few studies have been conducted on brain lesions in premature infants, by imaging especially by ultrasonography tranfontanellar [10] [11]. NZEH in a similar study rather concluded a predominance of periventricular leukomalacia [10]. The aim of this study was to identify the different brain lesions diagnosed in ultrasonography in premature newborn in Benin environment, and to study the epidemiological profile.

\section{Patients and Methods}

This is a descriptive cross-sectional study of analytical aiming conducted over a period of 6 months, from May $1^{\text {st }}$ to October $31^{\text {st }}, 2012$ in neonatology and medical scanning units of National Hospital University Centre koutoukou Hubert Maga (CNHU/HKM), Cotonou.

The purposive sampling has 105 premature newborn. We included in this study, preterm infants admitted to the neonatal unit during the study period and in whom ultrasonography transfontanellar was performed. Newborn whose gestational age was not precisely known and newborn with an infected central nervous system have been excluded from this study. We got the oral consent of the well-informed parents of each enrolled child. Preterm has been defined as a gestational age less than 37 weeks of amenorrhea (AW) at birth according to the World Health Organization [1]. Our sample is made of two groups: 37 newborn of very prematurity 28 - 32 AW and 68 newborn with moderate prematurity 33 - 36 WA.

The USG tranfontanellar was performed after aseptics having of skull to remove artifacts generated by the interposition aeric between the probe and the scalp. We used a X150 SIEMENS ACUSON echograph equipped with 2 probes, one convex 2 - $5 \mathrm{MHZ}$ and one linear 5 - $10 \mathrm{MHZ}$. The ultrasonography were performed newborn facing the operator, either in supine or sitting position on the lap of a parent to immobilize the head. After applying a linkage gel on the anterior fontanel, several reference cuts were performed:

The three cuts in the frontal plan included.

- An anterior cut from frontal horn of lateral ventricles for roof of lateral ventricles;

- A median cut passing through the third ventricle at the level of interventricular foramen through choroid to measure the size of lateral ventricles;

- A more posterior cut at level of interventricular foramen through the choroid plexus easily identified due to their high echogenicity.

It is also performed three cuts in the sagittal plan:

- A mid sagittal cut to get the third ventricle as a quadrangular, corpus callosum and the structures of the posterior fossa;

- Two Parasagittal cuts, right and left.

The standard of the examination is assessed on:

- The morphology and location of brain structures;

- The size and aspect of the ventricular cavity; 
- The normality of echostructure and echogenicity of the cerebral parenchymal;

- The aspect of pericerebral space and the absence of effusion on that level regarding the meninges. All the ultrasonographic tests were carried out by the same operator.

The different variables studied were: age, weight, cranial perimeter, brain anomalities objectified in the preterm. The statistical data were processed and analyzed by SPSS 20.0 software.

The intra ventricular hemorrhage was rated according to PAPILE classification into four grades. Grade 1: isolated sub-ependymal hemorrhage, grade 2: moderate intra ventricular hemorrhage and minimal or none ventricular dilatation, grade 3: intraventricular hemorrhage with ventricular dilation more or less important and grade 4: intraventricular hemorrhage associated with parenchymal lesions. Grades III and IV are the most pejorative and are associated with remote sequel [1] [9] [13].

\section{Results}

\subsection{Demographic and Epidemiological Features}

\subsubsection{Newborn Age When Implementing Ultrasonography Tranfontanellar}

The average age on the date of USG transfontanellar was $7.2 \pm 4.6$ days. Almost all ultrasonography tests accounting for $96 \%$ were made between 0 and 2 weeks (Table 1 ).

\subsubsection{Gestational Age at the Newborn Birth}

The most important gestational age of preterm was the one between 33 - 36 amenorrhea weeks (AW) accounting for $64.8 \%$ (Table 2).

\subsubsection{Birth Weight According to the Gestational Age}

The lowest birth weight $(<1500 \mathrm{~g})$ were in the rank of newborn whose term birth was less than $33 \mathrm{AW}$. There is a statistically significantly relationship between the birth weight and the gestational term $\mathrm{P}=0.0025$ (Table 3).

Table 1. Division of newborn according to the age (days) on the date of ultrasonography transfontanellar implementation.

\begin{tabular}{ccc}
\hline Âge (days) & Numbers & Frequency (\%) \\
\hline $0-3$ & 22 & 21.0 \\
$4-7$ & 40 & 38.1 \\
$8-14$ & 39 & 37.1 \\
$>14$ & 4 & 3.8 \\
Total & 105 & 100.0 \\
\hline
\end{tabular}

The average age on the date of ultrasonography transfontanellar implementation is $7.2 \pm 4.6$ days.

Table 2. Division of newborn according to the gestational age at birth.

\begin{tabular}{ccc}
\hline Birthterm (AW) & Numbers & Frequency (\%) \\
\hline $28-32$ & 37 & 35.2 \\
$33-36$ & 68 & 64.8 \\
Total & 105 & 100.0 \\
\hline
\end{tabular}

Average $=33.5 ;$ Standard deviation $=1.9$ AW .

Table 3. Division of newborn according to the birth weight and the gestational age at birth.

\begin{tabular}{cccc}
\hline \multirow{2}{*}{ Birthweight (g) } & \multicolumn{3}{c}{ Birthterm (AW) } \\
\cline { 2 - 4 } & $\mathbf{2 8 - 3 2}$ Total \\
\hline$<1500$ & 14 & $\mathbf{3 3} \mathbf{3 6}$ & 22 \\
$1500-2499$ & 23 & 54 & 77 \\
$\geq 2500$ & 0 & 6 & 6 \\
Total & 37 & 68 & 105 \\
\hline
\end{tabular}

$\mathrm{p}=0.0025$ 


\subsubsection{Cranial Perimeter According to the Gestational Age}

The average value of cranial perimeter was $30.7 \pm 2 \mathrm{~cm}$ in the very premature infants (28 - 32 AW) and $31.2 \pm$ $2.9 \mathrm{~cm}$ in average prematurity (33 - $36 \mathrm{AW})$. There was no statistically significantly relationship $(\mathrm{p}=0.184)$ between the average cranial perimeter and the gestational age in the two groups of prematurities (Table 4).

\subsection{Lesions Obseved in Ultrasonography Transfontanellar}

\subsubsection{Division of Lesions According to the Gestational Age}

The nasopharyngeal septum pellucidum was found in 46 premature infants, (Figure 1) followed by hemorrhages in 21 premature infants with grade 1 predominance in 14 newborn (Figure 2). Finally followed by ventricular leukomalacia perished in 4 newborn (Figure 3) (Table 5).

\subsubsection{Comparison of the Prevalence Rate in the Nasopharyngeal Septum Pellucidum According to Preterm Gestational Age}

We found $37.8 \%$ rate in the group between 28 - $32 \mathrm{AW}$, and $47.1 \%$ in the one between $33-36 \mathrm{AW}$, with $\mathrm{p}=$ 0.708 . The presence of nasopharyngeal septum is not related to the term of prematurity (Table 6).

\subsubsection{Comparison of the Prevalence Rate in Hemorrhages According to the Preterm Gestational Age}

We found in very preterm infants (28 - 32 AW) $40.5 \%$ rate of hemorrhage and in moderate premature $08.8 \%$ rate, with a statistically significantly relationship $\mathrm{p}<0.0001$. The hemorrhage was more frequent in the very premature infants than the moderates (Table 7).

Table 4. Minimal, maximal, average value and standard deviation of the newborns cranial perimeter according to gestational age.

\begin{tabular}{ccccc}
\hline \multirow{2}{*}{ Gestationalage (AW) } & \multicolumn{3}{c}{ Cranial perimeter } \\
\cline { 2 - 5 } & Min & Max & Average & Standard deviation \\
\hline $28-32$ & 25 & 33 & 30.7 & 2.0 \\
$33-36$ & 27 & 44 & 31.2 & 2.9 \\
\hline
\end{tabular}

$\mathrm{p}=0.184$, There is no statistically significantly relationship between the average cranial perimeter in the group of 28 - 32 AW and the one of $33-36$.

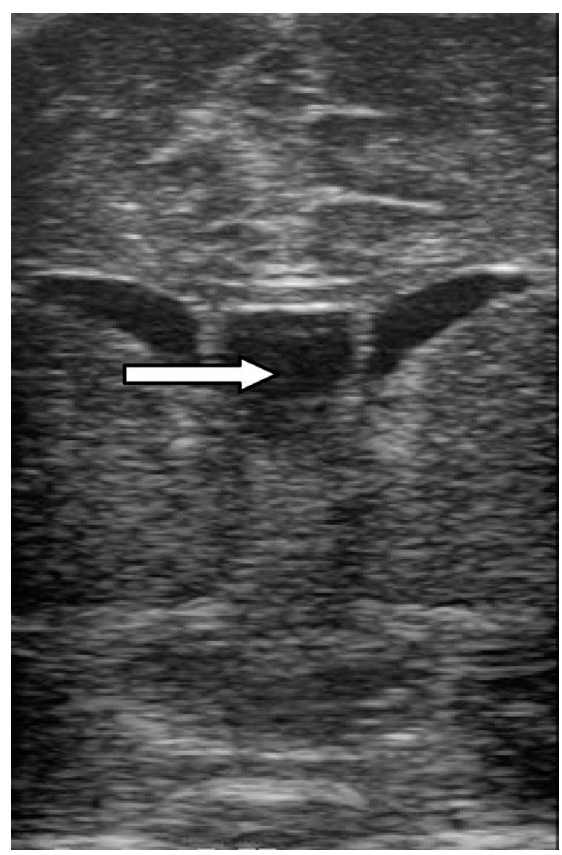

Figure 1. Coronal with nasopharyngeal septum pellucidum. 


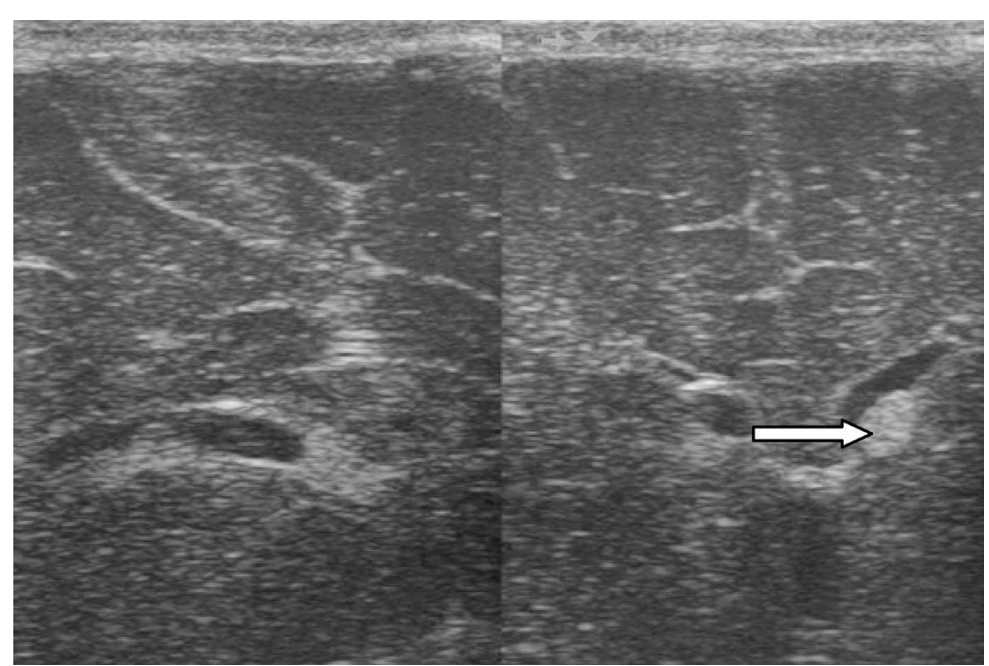

Figure 2. Sub-ependymal hemorrhage or grade 1 of the left frontal horn sagittal and coronal.

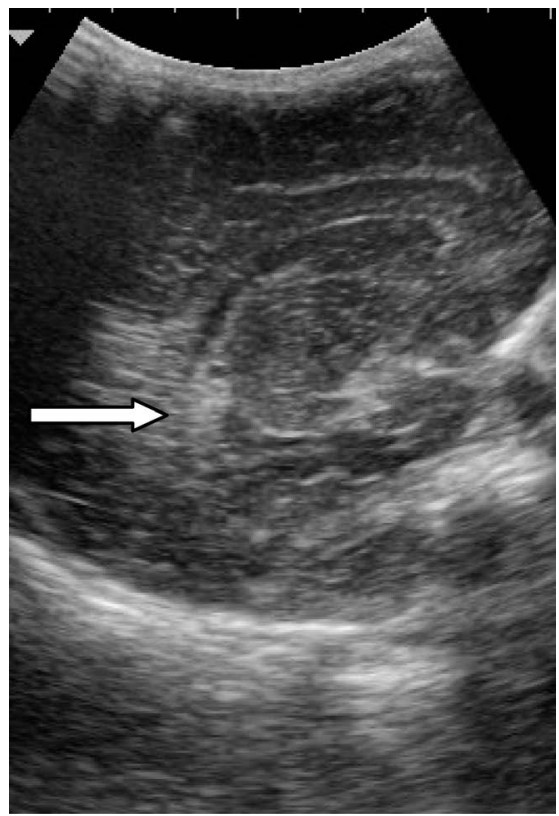

Figure 3. Sagittal lesion with hyperechoic periventricular leukomalacia.

Table 5. Division of premature newborns according to the pathological ultrasonographic results and the gestational age.

\begin{tabular}{cccc}
\hline Pathological ultrasonographic & \multicolumn{1}{c}{ Birthterm (AW) } & Total \\
\cline { 2 - 4 } Normal & $\mathbf{2 8 - 3 2}$ & $\mathbf{3 3} \mathbf{3 6}$ & 32 \\
Nasopharyngeal septum pellucidum & 2 & 30 & 46 \\
Haemorrhage grade I & 14 & 32 & 14 \\
Haemorrhage grade II & 10 & 4 & 5 \\
Haemorrhage grade III & 3 & 0 & 2 \\
Peri ventricular leukomalacia & 2 & 0 & 4 \\
Hydrocephalus & 4 & 0 & 2 \\
Total & 2 & 68 & 105 \\
\hline
\end{tabular}


Table 6. Comparison of the nasopharyngeal septum prevalence rate in preterm infants.

\begin{tabular}{cccc}
\hline Term (AW) & Presence of nasopharyngeal & Percentage & p \\
\hline $28-32$ & 14 & 37.8 & 0.708 \\
$33-36$ & 32 & 47.1 & \\
\hline
\end{tabular}

The presence of nasopharyngeal septum is not related to the prematurity term.

Table 7. Comparison of haemorrhages prevalence rate in preterm infants.

\begin{tabular}{cccc}
\hline Term (AW) & Haemorrhages & Percentage & p \\
\hline $28-32$ & 15 & 40.5 & $<0.0001$ \\
$33-36$ & 06 & 08.8 & \\
\hline
\end{tabular}

\section{The Limitation of Our Study}

Some difficulties have hindered our study, namely the movement of the very preterm infant soften dependents, and the poor financial resources of some parents that delay the completion on time of this work.

\section{Discussion}

The average age of newborns on the date of the ultrasonography was $7.2 \pm 4.6$ days. Almost all ultrasonography tests accounting for $90 \%$ was performed in the first two weeks of life. KUBAN in his study in the United States on 1053 preterm had precociously carried out as we do an ultrasonography transfontanellar that is before the fourth day of life 795 in preterm and 981 preterm before the end of the second week of life. He has been able to assess lesions of the white substances and ventricular hemorrhage in the premature [13]. It is the same in the study of SAVE and al [14] in Canada who assert that an ultrasonography transfontanellar performed by the second week of life provides the most complete and reliable diagnosis of hemorrhagic lesions. O'SHEA and al have recommended an ultrasonography routine in all preterm infants of gestational age $<30$ weeks. According to them, early USG transfontanellar is part of the basic parameters for test of these premature in neuro imaging [6]. Our study was conducted in these optimal conditions, which imply a reliability of our ultrasonographic tests in the diagnosis of early hemorrhagic lesions.

The division of newborns adopted in our study is superimposed on that of SONI and al [15]. It differs from the one of CHOWDHURY and al [16] in NewDelhi, who divided the premature newborn into four gestational age groups ranging from 28 to $36 \mathrm{AW}$ and SHAH and al in Bangladesh who classified their preterm into 3 groups such as the very premature 28 - $31 \mathrm{AW}$, the moderate preterm 32-34 AW and the light weight premature 35 - 36 AW [17]. Despite this difference in division in different studies, the predominance of preterm infants of 33 - 36 AW has been always found. This high rate of moderate premature compared to the very prematurity, may be due to better access to primary health care and adequate support for pregnant women in recent years in our localities, though far of that introduced in industrialized countries.

The average cranial perimeter in the very premature was $30.7 \pm 2 \mathrm{~cm}$ and $31.2 \pm 2.9 \mathrm{~cm}$ in the moderate premature. There was no statistically significantly difference $(p=0.184)$ between the cranial perimeter and the gestational age. SEMPE, by presenting the result of sequential study of the weight growth, height and the cranial perimeter of premature infants on a semi log graph and according to the age after birth, proved that most of the curves were almost straight, that the slope of the linear part was as higher as the prematurity was [18]. Our results could be explained by the reduced number of our preterm versus SEMPÉ.

The lowest birth weight $(<1500 \mathrm{~g})$ were found in the very premature of gestational age $<33$ weeks of amenorrhea, with a statistically significantly relationship between weight and gestational age $(p=0.0025)$. This report is found in the literature [1] [6] [10] [19]. According to these authors the birth weight is closely related to the gestational age. These preterm that gestational age $<28$ weeks had a very low weight $<1500 \mathrm{~g}$, and had the highest rate of hemorrhagic lesions, ventriculomegaly and the white substance abnormalities with neurological and behavioral sequel at the age of schooling.

The Cerebral ultrasonography exploration revealed various intracranial lesions. The nasopharyngeal septum pellucidum (46 cases), intraventricular hemorrhage (21 cases) dominated by that of grade I (14 premature), the ventricular leukomalacia perished (4 cases) and the hydrocephalus ( 2 cases). These pathologies identified, ex- 
cept the nasopharyngeal septum pellucidum, are especially severe in the very prematurity 28 - 32 AW. The usefulness of ultrasonography in the detection and prognosis of early brain lesions is highly reported in the literature [1] [6] [9] [13]. Chowdhury et al. [16] stressed that cerebral ultrasonography has enable them to detect $12 \%$ of intracranial pathology in their study. The nasopharyngeal septum pellucidum highly found in our series (63\%) was less reported in the literature. Chowdhury et al. [16] had identified in premature a similar rate of $68 \%$ like us. However, let's note that there was no statistically significantly difference $(P=0.708)$ between prematurity and the presence of nasopharyngeal septum pellucidum. According to the literature, the nasopharyngeal septum pellucidum would result from the non-fusion of the two plates that form the septum pellucidum. It would therefore be a persistence of the existing fluid space during foetal life [20] [21]. It is considered as a variant of the standard. According to LOWE, this singularity would not be symptomatic and would not require treatment (e.g. drain) [21]. It would be common among preterm infants and at 50\% in term newborns [22]. The intraventricular hemorrhage and periventricular leukomalacia was predominant in the very premature newborn, especially hemorrhage with $P<0.0001$ as reported by most of authors [1] [9] [11] [13] [19]. According to them, they second the immaturity of brain structures in premature newborn. In our series, the grade I was found at $66.6 \%$, followed by $24 \%$ in grade 2 . Unlike NZEH [10], the periventricular leukomalacia was slightly found in our series as noncystic.

Prematurity can cause a range of disabilities and neurodevelopmental disabilities, including behavioral problems and long-term learning difficulties among survivors. The frequency and severity of its complications were higher with a low gestational age [1] [5] [17]. Further studies could assess in long term the future of premature in Africa.

Although ultrasonography test is appropriate for intra cerebral hemorrhage, lesions analysis of white substances by this technique would remain lower than Magnetic Resonance Imaging [9] [13] [19], which would constitute a best and available alternative in industrialized countries.

\section{Conclusion}

The anomalies found in ultrasonography transfontanellar in preterm are dominated by nasopharyngeal septum pellucidum, intraventricular hemorrhage (largely that of grade I) and ventricular leukomalacia perished. They often predominated in the very preterm of low weight. Our results are superimposed on the western literature data. A further Magnetic Resonance Imaging study would help to better understand the anomalies of the white substance in premature in Benin and the future of these premature in long-term.

\section{References}

[1] Blencowe, H., Cousens, S., Chou, D., Oestergaard, M., Say, L., Moller, A.-B., et al. (2013) Born Too Soon: The Global Epidemiology of 15 Million Preterm Births. Reproductive Health, 10, S2. http://dx.doi.org/10.1186/1742-4755-10-S1-S2

[2] Beck, S., Wojdyla, D., Say, L., Bertran, A.P., Merialdi, M., Requejo, J.H., et al. (2010) The Worldwide Incidence of Preterm Birth: A Systematic Review of Maternal Mortality and Morbidity. Bulletin of the World Health Organization, 88, 31-38. http://dx.doi.org/10.2471/BLT.08.062554

[3] Black, E., Cousens, S., Johnson, H., Lawn, E., Rudan, I., Bassani, D., et al. (2010) Regional and National Causes of Child Mortality in 2008: A Systematic Analysis. Lancet, 375, 1969-1987. http://dx.doi.org/10.1016/S0140-6736(10)60549-1

[4] D’Almeida, M., Bagnan, L., Alao, M.J., Alihonou, F. and Ayivi, B. (2011) Utilité de l'examen systématique du nouveau-né au CNHU de Cotonou au Bénin. Mali Medical, 26, 8-11.

[5] Berteloite, C.E. (2009) Les séquelles à l’âge scolaire d’un ancien grand prématuré. Faculté de Médecine, Mémoire de Psychomotricité, Toulouse.

[6] O’Shea, M.T., Kuban, K.C.K., Allred, E.N., Paneth, N., Pagano, M., Dammann, O., et al. (2008) National Cranial Ultrasound Lesion and Developmental Delays at 2 Years of Age among Extremely Low Gestational Age Children. Pediatrics, 122, e662-e669. http://dx.doi.org/10.1542/peds.2008-0594

[7] Jabnoun, S., Kacem, S., Chabchoub, A., et al. (2000) Les troubles hémorragiques du nouveau-né à propos de 529 cas. Review of Maghreb Pediatric, 10, 27-35.

[8] Habzi, A., Benomar, S., Lahbabi, M., et al. (2001) Les hémorragies intra-Crâniennes du nouveau-néàtermeàpropos de 23 cas. Médecine du Maghreb, 88, 33-37. 
[9] Larroque, B., Ancel, P.-Y., Marrets, M.L., Andre, M., et al. (2008) Arnaudc Neurodevelopmental Disabilities and Special Care of 5 Year Old Children Born before 33 Week of Gestation: A Longitudinal Cohort Study. Lancet, 371, 813820. http://dx.doi.org/10.1016/S0140-6736(08)60380-3

[10] Nzeh, D. and Ajavi, O.A. (1997) Sonographic Diagnosis of Intracranial Hemorrage and Periventricular Leukomalacia in Premature African Neonate. European Journal of Radiology, 26, 77-82. http://dx.doi.org/10.1016/S0720-048X(96)01151-5

[11] Faye, B.-F., Sylla, A., Seckm, M., Salla, A., Tourea, O. and Gueye, N.-R. (2013) Aspects diagnostique et évolutif des syndromes hémorragiques du nouveau-néà Dakar. Archives de Pédiatrie, 20, 164-170. http://dx.doi.org/10.1016/j.arcped.2012.11.010

[12] Brouwer, M.J., De Vries, L.S., Groenendaal, F., Koopman, C., Pistorius, T.R. and Mulder, E.J. (2012) New Reference Values for the Neonatal Cerebral Ventricles. Radiology, 262, 224-233. http://dx.doi.org/10.1148/radiol.11110334

[13] Kuban, K.C., Allred, E.N., Michael, T.O., Paneth, N., Pagano, M. and Dammann, O. (2009) Cranial Ultrasound Lesions in the NICU Predict Cerebral Palsy at Age 2 Years in Children Born at Extremely Low Gestational Age. Journal of Child Neurology, 24, 63-72. http://dx.doi.org/10.1177/0883073808321048

[14] Sauve, R. (2001) Le dépistage systématique par échographie transfontanelle pour prévoir les issues neurodéveloppementale à long terme des prématurés. Paediatrics and Child Health, 6, 47-52.

[15] Soni, J.P., Singhania, R.U. and Sharma, A. (1992) Measurements of Ventricle Size by Term and Preterm Infants. Indian Pediatrics, 29, 55-59.

[16] Chowdhury, V., Gulati, P., Arora, S. and Thirupuram, S. (1992) Cranial Sonography in Preterm Infants. Indian Pediatrics, 29, 411-415.

[17] Shah, R. and Mulleny, L.C. (2014) Incidence and Risk Factors of Preterm Birth in a Rural Bangladeshi Cohort. BMC Pediatrics, 14, 112. http://dx.doi.org/10.1186/1471-2431-14-112

[18] Sempe, M. (2015) La croissance humaine http://www.accroissements-michel-sempey.fr/chap-perimetres/223-la-croissance-du-perimetre-crânienconsultéle21/12/ 2015à02h05

[19] Davis, A.S., Hintz, S.R., Ricki, F., Goldstein, R.F., Ambalavanan, N. and Bann, C.M. (2014) Outcomes of Extremely Preterm Infants Following Severe Intracranial Hemorrhage. Journal of Perinatology, 34, 203-208. http://dx.doi.org/10.1038/jp.2013.162

[20] Farrugia, S. and Babcock, D.S. (1981) The Cavum Septi Pellucidi: Its Appearance and Incidence with Cranial Ultrasonography in Infancy. Radiology, 139, 147-150. http://dx.doi.org/10.1148/radiology.139.1.7208915

[21] Lowe, L.H. and Bailey, Z. (2011) State-of-the-Art Cranial Sonography: Part 2, Pitfalls and Variants. American Journal of Roentgenology, 196, 1034-1039.

[22] Wildi, G., Pizzolato, G.P. and Djientcheu, V. (2002) Le cavum septi pellucidi: De l'embryologie à la neurochirurgie. Schweizer Archiv für Neurologie und Psychiatrie, 253, 51-68. 